\title{
Periodontal regeneration: is it still a goal in clinical periodontology?
}

\author{
Joni Augusto CIRELLI(a) \\ Tiago FIORINI(b) iD \\ Carlos Heitor Cunha MOREIRA(c) \\ Rafael Scaf de MOLON(a) \\ Tamires Pereira DUTRA(d) iD \\ Enílson Antonio SALLUM(d) iD \\ (a) Universidade Estadual Paulista - Unesp, \\ School of Dentistry at Araraquara, \\ Department of Diagnosis and Surgery, \\ Araraquara, SP, Brazil. \\ (b) Universidade Federal do Rio Grande do Sul \\ - UFRGS, School of Dentistry, Department \\ of Conservative Dentistry, Porto Alegre, \\ RS, Brazil. \\ (c) Universidade Federal de Santa Maria - \\ UFSM, School of Dentistry, Department of \\ Stomatology, Santa Maria, RS, Brazil. \\ (d) Universidade Estadual de Campinas \\ - Unicamp, Piracicaba Dental School \\ - Department of Prosthodontics and \\ Periodontics, Piracicaba, SP, Brazil.
}

Declaration of Interests: The authors certify that they have no commercial or associative interest that represents a conflict of interest in connection with the manuscript.

Corresponding Author:

Joni Augusto Cirelli

E-mail: joni.cirelli@unesp.br

https://doi.org/10.1590/1807-3107bor-2021.vol35.0097

Submitted: March 10, 2021

Accepted for publication: March 31, 2021

Last revision: April 13, 2021
Abstract: In the last decades, Periodontal Regeneration has been one of the most discussed topics in Periodontics, attracting the attention of researchers and clinicians. This can be justified by the evident and continuous progress observed in the field, characterized by a better understanding of the biological mechanisms involved, significant improvement of operative and technical principles, and the emergence of a wide range of biomaterials available for this purpose. Together, these aspects put the theme much in evidence in the search for functional and esthetic therapeutic solutions for periodontal tissue destruction. Despite the evident evolution, periodontal regeneration may be challenging and require the clinician to carefully evaluate each case before making a therapeutic decision. With a critical reassessment of the clinical and preclinical literature, the present study aimed to discuss the topic to answer whether Periodontal Regeneration is still a goal in clinical periodontology. The main aspects involved in the probability of success or failure of regenerative approaches were considered. A greater focus was given to intrabony and furcation defects, clinical conditions with greater therapeutic predictability. Aspects such as more appropriate materials/approaches, long-term benefits and their justification for a higher initial cost were discussed for each condition. In general, deep intrabony defects associated with residual pockets and buccal/lingual class II furcation lesions have predictable and clinically relevant results. Careful selection of the case (based on patient and defect characteristics) and excellent maintenance are essential conditions to ensure initial and long-term success.

Keywords: Periodontics; Periodontal Diseases; Bone and Bones; Regeneration; Furcation Defects.

\section{Introduction}

The present special issue of Brazilian Oral Research addresses important topics that Periodontology has been dealing with for a long time. The idea here is not only to compile studies and findings but rather to reassess preclinical and clinical data, interpreting results in a meaningful way for daily clinical practice. In this regard, the question of whether periodontal regeneration is still a goal in clinical periodontology emerges as an opportunity to rethinking our beliefs and practices based on a more comprehensive and mature appraisal of the evidence. 
Attempts to regenerate periodontal tissues go back to the nineteenth century. ${ }^{1}$ However, it was only from seminal works from professors Tony Melcher in the US and Stüre Nyman \& Thorkild Karring in Scandinavia, in the late 70 's and early 80 's, that the modern periodontal regeneration concept was established. Thenceforth, a quest for the "Holy Grail", the material and/or technique that would re-establish lost structures, was carried out, with remarkable learned lessons and several misunderstandings along the way. ${ }^{2}$

According to the classical definition, periodontal regeneration is a histological concept where all tooth-supporting tissues (i.e., cementum, periodontal ligament, and alveolar bone) are reconstructed similarly to the originally lost tissues. This definition has two relevant implications that should be highlighted to put facts into perspective. First, histological proof of periodontal regeneration in humans is relatively scarce due to obvious ethical reasons, so most of the gathered knowledge is based on preclinical studies. Although one may interpret this as a weakness of the evidence, it is actually the other way around: a careful analysis based on solid and reliable preclinical models allows us to separate biological facts from clinical illusions. Second, in some situations, the fulfillment of the classical definition is not achievable or even necessary, since satisfactory outcomes may be achieved with these "regenerative procedures" for both clinicians and patients alike. From the patient's perspective, changes in perceivable outcomes, including tooth loss, tooth mobility, or oral health-related quality of life, may be more relevant than other surrogate outcomes, like periodontal probing depth or the histological constitution of the tissues.

Therefore, during this text, we will adopt a broader "clinical" definition of periodontal regeneration. This definition includes not only the classical histological concept but also considers the use of different grafts, biomaterials, biological agents, or combinations of them in the defects. For instance, although bone substitute grafts often result in a less vascularized structure resembling a scar tissue (biomaterial particles involved in a dense fibrovascular matrix), which clearly does not fulfill the classical definition, this may impact the abovementioned harder outcomes that are relevant to patients. The basic concepts that guide wound healing and ultimately define clinical choices will be presented and discussed. The following additional points will be addressed:

a. What is the clinical importance of treating periodontal defects (more specifically, intrabony and furcation defects) with regenerative procedures?

b. What can we achieve with the current regenerative materials/approaches?

c. Is it possible to maintain the benefit in the long term?

d. Does this benefit justify the greater initial costs? Finally, there will be a debate on what is clinically relevant (mainly from the patient's perspective) and what is predictably achievable to answer the title question.

\section{Basic concepts of wound healing}

The basic requirements for proper oral wound healing are the same that are necessary for wound healing in other body tissues: the wound needs to be clean and stable (allowing clot formation/adherence), and the wound edges have to be closed together without tension, which is also known as primary intention healing. Another aspect is crucial for the success of periodontal regenerative procedures: a space providing structure that allows new tissue formation to occupy the lost tissues is necessary. ${ }^{3}$ Although these three aspects are well known and frequently targeted, they are often not achieved due to many factors (local and systemic) hampering the ideal regeneration scenario. Knowing these limiting factors that hinder healing/regeneration is the key to success.

\section{Flap management}

From a historical perspective, periodontal surgical procedures have aimed to clean the tooth surface by removing granulation tissue and exposing the underlying regenerative resources. They often comprised invasive approaches, including resective techniques and tissue excision. These techniques may damage blood supply, which results in fewer progenitor cells in the surgical site and delays and compromises healing. Analysis of blood flow changes 
after surgical procedures by laser Doppler flowmetry revealed that baseline perfusion levels were only observed 15 days later. ${ }^{4}$ Comparison of standard methods and less invasive techniques, including Widman flap versus papilla preservation techniques ${ }^{5}$ or microsurgery procedures versus macro surgery, ${ }^{6}$ demonstrated that minimally invasive approaches result in reduced trauma, faster healing, and better clinical outcomes.

\section{Space provision}

Based on Tony Melcher's findings about the regenerative potential of different periodontal cell types, $^{7}$ the conviction that a barrier device was necessary to mechanically restrict the "wrong" cells (i.e., epithelial and gingival connective cells, which have a faster turnover rate) and favor PDL cells, cementoblasts, and osteoblasts was absorbed unequivocally. The concept of Guided Tissue Regeneration (GTR) arose based on this premise, and the development of membranes/barriers and scaffolds was embraced by the industry. However, preclinical studies comparing occlusive and macroporous membranes demonstrate clinically relevant results for both therapies. ${ }^{8,9}$ It seems that as crucial as physically delaying the migration of epithelial cells is guaranteeing space provision and wound stability, mainly in non-contained defects. Indeed, a linear relationship between the space provided by barriers and the amount of regenerated tissue has been observed. ${ }^{10,11}$ Also, limited regeneration was observed when these devices got exposed..$^{12}$ Therefore, not only providing but maintaining this space undisturbed is essential for good clinical results.

\section{Wound stability}

As soon as the flap margins are closed together, a delicate fibrin clot matrix is formed, allowing initial cell migration. However, mechanical forces from chewing and speech muscles constantly defy the stability of this clot matrix, thus jeopardizing periodontal regeneration. Wikesjö and coworkers evaluated this principle's impact by compromising clot adhesion using heparin solutions over the root surface. Indeed, they observed that root treated in this manner displayed formation of a long junctional epithelium, whereas control sites exhibited more connective tissue and cement formation. . $^{13,14}$

\section{Primary intention healing}

As seen above, maintaining the structural strength of the wound is mandatory to provide space for tissue regeneration and allow clot stability. To complete the basic requirements necessary to achieve successful periodontal regeneration, the primary intention healing is required. Therefore, delicate surgical handling aiming at passive flap adaptation should be planned and executed in a way that avoids compromising the vascular support of the wound. It is important to highlight that during the initial events of healing, the structural integrity of the wound depends mostly on sutures. The tensile strength of the gingival flap, a measure of resistance, remains low a week after the surgery, and only after 14 days does it reach values that are compatible with wound-rupturing resisting levels. ${ }^{15}$ Bacterial contamination and degradation of suture material and the size of the inflammatory infiltrate beneath the incision lines also play a role in the wound's stability. As a practical implication, the choice of the suture material (favoring materials that produce less inflammation), the type and number of sutures (including suture techniques that cover more extensive amounts of tissue and provide flap stabilization), and suture removal time (avoiding less than ten days) should be considered. ${ }^{3}$

Taken together, these aspects make up the optimal conditions to achieve periodontal regeneration and reveal some of the factors that threaten the success of the therapy, including vascular damage, mechanical stress through the flap generating wound instability, infections, and systemic factors limiting immune response. A comprehensive analysis of the clinical scenario will help answer the title question, pointing to situations where periodontal regeneration is both clinically relevant and predictable. Following, we will address the two main clinical circumstances where regenerative therapy has been used: intrabony and furcation defects.

\section{Intrabony defects}

Infrabony defects show the base of the pocket positioned apically to the level of the alveolar crest and 
could be typified as intrabony (i.e., located in primarily one tooth) and craters (i.e., involving two adjacent root surfaces with a similar amount of bone loss on the two adjacent teeth). ${ }^{16}$ The number of remaining bony walls is used to classify intrabony defects as three-, two-, or one-wall defects. ${ }^{16,17,18}$ However, it is common to observe three-wall defects apically while the bone has been destroyed in the superficial portion, leaving a two- or one-wall component (combination defects). ${ }^{16,17}$ Their reported frequency varies significantly $(8 \%$ to $51 \%) \cdot{ }^{16,18-25}$

\section{What is the clinical importance of treating intrabony defects with regenerative procedures?}

It is generally accepted that residual periodontal pockets around a tooth $(\geq 5 \mathrm{~mm}$ and bleeding on probing) represent a risk factor for tooth loss. ${ }^{26,27} \mathrm{~A}$ high frequency of tooth loss among teeth associated with angular bony defects has been observed..$^{22,26,27}$ Sites with uneven bone architecture are thought to be more frequently associated with the persistence of periodontal pockets. Therefore, the importance of treating intrabony defects can be related to the need to decrease probing depths and eliminate bleeding on probing, increasing clinical attachment/bone and improving periodontal support and maintenance. The overall idea is to change tooth prognosis. In addition, this goal should be achieved with no or minimal gingival recession after therapy, especially in esthetic areas. The importance of periodontal defects as a factor that increases complexity in managing periodontal clinical cases has been incorporated into the proposed classification of periodontitis (matrix based on stage and grade) and deserves attention from all clinicians. ${ }^{28}$

\section{What can be achieved with the current available materials/approaches in intrabony defects?}

Improvements beyond those obtained with access flap alone when using regenerative approaches to treat intrabony defects can be expected. ${ }^{29-34}$ Histologically, in pre-clinical studies, the percentage of periodontal regeneration observed ranged from $12 \%$ to $75 \%$, with the best results for autografts. ${ }^{31,35}$ Biomaterial-related adverse effects have not been reported. ${ }^{31}$ Therefore, flaps with the most tested biomaterials (alone or in combination) may promote greater periodontal regeneration than flaps without these biomaterials. ${ }^{31}$ In human histological studies, the percentage of defects showing periodontal regeneration ranged from $34 \%$ to $80 \%$ after different biomaterials (autografts $=80 \%$, allograft $=70 \%$, xenograft $=70 \%$, alloplastic $=34 \%$, barriers $=75 \%$, biologics $=45 \%$, and combinations $=75 \%) .35$ Therefore, there is evidence that periodontal regeneration is achievable to a variable extent in humans after different approaches. ${ }^{35}$. Regarding additional clinical benefits, there are many systematic reviews focusing on regenerative approaches. ${ }^{30,33,35-59}$

GTR with non-resorbable and resorbable membranes presented similar clinical and radiographic outcomes. ${ }^{60}$ However, due to the need of a second surgery and complications associated with non-resorbable barriers, they seem to be less used nowadays. ${ }^{33}$ GTR provides greater clinical attachment level (CAL) gain and more probing pocket depth (PPD) reduction than open flap debridement (OFD) for intrabony defects. ${ }^{33,47,48,55,60}$ The combination with bone substitutes (BS) is based on the occasional need to support the membrane. Combination therapies provided slightly greater clinical attachment level gain than enamel matrix derivative (EMD) or membranes alone. ${ }^{61}$ Furthermore, GTR with bone graft (BG) provided the greatest defect fill. ${ }^{61}$ Bone grafts/substitutes may positively influence bone levels, increase the attachment level and reduce probing depths when compared to OFD. ${ }^{53}$.

The use of EMD for periodontal regeneration is based on the strategy of mimicking specific events occurring in the development of periodontal supporting tissues. An additional benefit (CAL gains and PPD reductions) was reported for an EMD-treated group when papilla preservation flaps with and without EMD were compared. ${ }^{62}$. However, another study concluded that EMD did not provide additional improvements. ${ }^{63}$ These different conclusions exemplify the variability observed when evaluating regenerative approaches that can be under the influence of many factors (e.g. patient, defect, and surgical factors). A previous review explored the comparison of EMD with OFD, GTR, and bone grafts. ${ }^{40}$ EMD provided statistically significant CAL improvements and PPD 
reduction compared to placebo/control. However, a high degree of heterogeneity was seen. GTR showed more complications during the postoperative period than EMD, but no clinically relevant differences were observed. ${ }^{40}$ The use of a filler material may be associated with less recession than EMD. ${ }^{40}$ A recently published review ${ }^{33}$ included 79 randomized clinical trials and performed 13 meta-analyses. EMD was superior to OFD in improving CAL, PPD reduction, and bone gain, while recession was not different between the approaches. Substantial to considerable heterogeneity was observed. The conclusion was that flaps with papillary preservation combined with EMD or membranes should be considered the preferable treatment for residual pockets associated with deep ( $\geq 3 \mathrm{~mm}$ ) intrabony defects.

The space-making characteristics of a material are deemed important when facing deep non-contained intrabony defects and, in such cases, EMD alone may not be sufficient. Therefore, the combination of EMD with BG has been considered. It has been shown that the combination may result in further clinical improvements when compared to EMD alone. ${ }^{45}$ The addition of Deproteinized Bovine Bone Mineral (DBBM) may improve the results of resorbable membranes and EMD. ${ }^{33}$

The guideline of the European Federation of Periodontology (EFP) for the treatment of stage I-III periodontitis includes the recommendation of treating residual deep pockets associated with intrabony defects ( $\geq 3 \mathrm{~mm}$ ) with either GTR or EMD, with or without the addition of bone grafts. The decision of using the combination approach should be based on the defect morphology.64 An important observation is that access flaps, including papillary preservation procedures, may enhance clinical results.

Regarding factors that can interfere with treatment outcomes, smoking and poor oral hygiene are associated with reduced attachment level gains following regenerative therapy. ${ }^{29,32}$ In terms of anatomical factors, deep and shallow defects have shown a similar percentage of clinical attachment gain. ${ }^{65}$ Studies using membranes ${ }^{66}$ and enamel matrix derivative ${ }^{67}$ have shown that defects with smaller angle gained significantly more attachment in comparison with wider defects after one year. However, a multicenter study indicated reduced impact of the angle on CAL gain after one year with a combined treatment using membrane and BG. ${ }^{68}$ Defects with three walls achieved better outcomes. ${ }^{29}$ However, it seems that the negative impact of the number of residual walls is reduced when minimally invasive surgical techniques associated with amelogenins are used. ${ }^{69}$ Regarding endodontic status, vital or properly endodontically treated teeth do not seem to be detrimental to the outcome of regenerative therapy. ${ }^{29,32}$ Severe and uncontrolled tooth mobility may impair regenerative outcomes. ${ }^{29,32}$

\section{Is it possible to maintain this benefit in the long term?}

It has been reported that the greater PPD reduction and CAL gain achieved with regenerative surgeries after one year have lasting effects for 5 to 10 years. ${ }^{34}$ The results after 20 years of regenerative treatment were compared to access flap surgery in a follow-up study. ${ }^{70}$ The re-intervention costs during this period were reported. The study included three groups ( $n=15$ per group), two of which received regenerative treatment. Subjects with a deep interproximal intrabony defect were randomized in the following groups: modified papilla preservation technique with titanium-reinforced expanded polytetrafluoroethylene (e-PTFE) membranes; access flap plus e-PTFE barriers, and flap alone (Modified Widman Flap). Supportive periodontal treatment was provided monthly during the first year and every 3 months during the remaining period. Additional therapy was provided for sites with recurrences. Forty-one subjects were analyzed after 20 years. The areas treated by flap alone showed more attachment loss compared to the sites treated by regenerative approaches. The group treated by flap alone lost two teeth, while no tooth loss was observed in the regenerative groups. In terms of recurrence, fifteen episodes of recurrence occurred in the flap alone group, five in the group treated by papilla preservation with reinforced e-PTFE barriers, and six in the flap plus e-PTFE barriers. The number of recurrences was correlated with the depth of the residual pockets at one year. More persistent pockets at the end of the active treatment were observed in the flap group. The initial procedure costs were 
higher for regenerative therapy than flap alone, but charges with re-intervention were higher for flap alone. Therefore, regenerative approaches may provide better long-term outcomes compared to access flap alone and fewer expenses related to re-intervention, but the higher immediate cost of the regenerative treatment should be considered. Larger studies are necessary to extend these observations.

\section{Does this benefit justify the greater initial costs?}

When the case selection is made judiciously (patient/site factors), the surgical procedure is performed correctly, and the chosen material (s) has previous histological/clinical evidence of additional regenerative effect, the benefit may justify the greater initial cost. This view is based on the expectation of fewer recurrences and lower risk of disease progression, with the possibility of increased tooth support after regenerative procedures. It should be considered that tooth replacement costs with tooth-supported or implant-supported prostheses are generally high. ${ }^{70}$

Therefore, periodontal regenerative procedures (GTR, EMD, with or without BG) are part of the current clinical armamentarium used to treat residual pockets associated with deep intrabony defects $(\geq 3 \mathrm{~mm})$, after careful case selection and in conjunction with papillary preservation flaps. ${ }^{64}$

An interesting point that merits attention is the possible impact of flap design on outcomes after periodontal regenerative treatment. When minimally invasive techniques were associated with biomaterials, no significant differences were observed in clinical outcomes compared to controls (without biomaterials). ${ }^{33,71}$ Therefore, the potential of minimally invasive surgical approaches in the treatment of periodontal intrabony defects should be further explored in well-designed clinical and histological studies.

\section{Furcation defects}

The furcation involvement is clinically characterized by bone destruction induced by periodontal disease in the separation zone of the roots, both vertically and horizontally, into the bi- or trifurcation area of multi-rooted teeth. ${ }^{72}$

Among the various existing classifications of furcation defects, those proposed by Hamp et al. ${ }^{73}$ and Tarnow and Fletcher ${ }^{74}$ are currently the most used. These classifications are primarily based on the horizontal and vertical extension of the furcation involvement. In the Hamp et al. ${ }^{73}$ classification, furcation involvements are categorized as degree I to III, which vary according to the extension of horizontal bone destruction: degree I: horizontal bone loss up to $3 \mathrm{~mm}$; degree II: bone loss exceeding $3 \mathrm{~mm}$; and degree III: horizontal bone destruction from the buccal side to the lingual/palatal (or proximal) side ("through-and-through" destruction). ${ }^{73}$ Additionally, Tarnow and Fletcher ${ }^{7}$ subclassified furcation involvement based on the vertical bone loss between the base of the defect and the furcation roof in subclasses $A(0-3 \mathrm{~mm}), \mathrm{B}(4-6 \mathrm{~mm})$ and $\mathrm{C}(>7 \mathrm{~mm})$.

\section{What is the clinical importance of treating furcation defects with regenerative procedures?}

Multi-rooted teeth with interradicular loss of periodontal tissue present impaired long-term prognosis in untreated patients and increased risk of additional attachment loss, which may ultimately lead to tooth loss. ${ }^{75,76}$ Classical epidemiological longitudinal studies have shown that the molars are the most extracted teeth during periodontal maintenance after active therapy, with loss average ranging from $23 \%$ to $57 \%$ of molars affected with furcation involvement, in periods varying from 15 to 22 years. ${ }^{77-80}$

In a retrospective study evaluating long-term results after periodontal therapy, molars with furcation involvement presented 3 to 7 times more risk of periodontitis progression and tooth loss compared to molars without furcation involvement. Furthermore, smoking and lack of compliance with supportive periodontal therapy account for increased risk of progressive bone loss in the furcation region. ${ }^{81}$

All those epidemiological studies pointed to the crucial role that furcation involvement plays in periodontitis progression and tooth loss. In this context, the correct approach for the treatment of this type of defect will benefit the prognosis of the involved tooth. 


\section{What can we achieve today with the current materials/approaches in furcations?}

Treatment of furcation-involved teeth represents one of the greatest clinical challenges in periodontal therapy due to the variable morphology and complex anatomy of the defects. ${ }^{81,82,83}$ The treatment strategies for furcation defects range from a less invasive approach, i.e., non-surgical periodontal therapy, to more invasive therapies: $O F D$, regenerative procedures ${ }^{84}$ resective techniques ${ }^{85}$ like tunneling, root resection, hemisection, and even extraction followed by implant placement. ${ }^{86}$ Class I furcation defects can be successfully treated with conventional periodontal treatment through scaling and root planing (SRP) and represent a minimum risk factor for tooth loss. ${ }^{78,79,80}$ On the other hand, class II and III furcations, in most instances, require a surgical approach to manage the consequential defects, as these conditions are associated with increased risk of further periodontal breakdown and tooth loss compared to non-involved teeth. ${ }^{77,78,79,80}$

Nevertheless, non-surgical treatment comprising supra and subgingival SRP with manual or ultrasound devices and patient instruction/motivation to control biofilm and associated risk factors (smoking cessation, hyperglycemia control, dietary counseling, etc.) should precede any surgical approach. ${ }^{64}$

The introduction of BG materials and the concept of GTR offered new treatment alternatives for more predictable management of furcation involvement aiming at furcation closure by the formation of new bone, cementum, and periodontal ligament. ${ }^{53,87}$ More recently, the advent of biologic agents such as EMD, growth factors like rhBMP2 (recombinant human bone morphogenetic protein-2), rhPDGF (recombinant human platelet-derived growth factor), TGF- $\beta$ (transforming growth factor beta), and APC (autologous platelet concentrates) has given new hope for enhanced outcomes. ${ }^{2}$ However, to date, no regenerative approach has provided clinically relevant benefits in the treatment of class III furcations, ${ }^{88,89}$ which makes resective techniques better therapeutic alternatives for them. ${ }^{84,85}$ Therefore, the most predictable indication for regenerative therapy is for the treatment of class II furcation involvement. ${ }^{84,85}$
Since the ' 80 s, a vast literature has addressed the regenerative approaches for class II furcation defects. BS were the first biomaterials used for this purpose and, in general, most of the studies demonstrated superior clinical outcomes when BS was compared to non-regenerative approaches. However, the wide variety of materials and techniques precludes a conclusive interpretation of the benefits of BS alone as the treatment for class II furcation..$^{53}$

On the other hand, GTR has been extensively evaluated as a regenerative therapy for class II furcation. According to a systematic review (SR) that included 34 randomized clinical trials, ${ }^{90}$ GTR using resorbable and non-resorbable membranes provided significant clinical impact on defect closure and periodontal attachment gain in class II furcation defects. Non-resorbable and resorbable membranes revealed substantial improvement in vertical probing reduction, attachment gain, horizontal bone fill, and vertical bone fill compared to OFD. These data suggest that GTR was more effective in the management of class II furcation defects compared to OFD,, 0 corroborating a previous SR of randomized clinical trials. ${ }^{87}$ Also, two other SRs demonstrated superior clinical benefits when GTR is associated with BS, in comparison with membranes or BS alone. ${ }^{60,91}$

EMD has been the most evaluated biologic agent for treatment of class II furcation defects so far. ${ }^{44,92}$ Constituted of proteins, mainly amelogenins, EMD plays an important role in the induction of cementum formation and angiogenesis, while modulating wound healing in periodontal tissues, ${ }^{93}$ features that are the rationale for using it in furcation defects. According to a recent $S R$, the use of EMD in conjunction with bone grafts, or OFD and/or GTR, improved attachment gain and the number of class II conversion to class I furcations. ${ }^{93,94}$

More recently, Jepsen et al. ${ }^{84}$ investigated the effectiveness of regenerative procedures (barrier membranes, bone replacement graft, EMD, and their combinations) in the treatment of furcation involvement and compared to OFD in a systematic review. This review included 20 randomized clinical trials (19 in class II defects) with a total of 787 defects. The authors concluded that regenerative procedures were more efficient than OFD for the treatment of 
class II furcation involvement. With this treatment modality, it is possible to expect furcation closure or class I conversion improving the clinical outcomes in class II furcation involvements. In ten clinical trials, furcation closure ranged between $0 \%$ to $60 \%$, and in six trials the conversion to class I furcation varied from $29 \%$ to $100 \%$. Regenerative techniques were superior to OFD for furcation defect improvement, horizontal and vertical attachment level gain, and reduction in PPD. The combined approach, including non-resorbable membranes plus BG, was classified as the best treatment for vertical attachment level gain and PPD reduction, especially in class II mandibular molar furcation. ${ }^{84}$ Accordingly, the $\mathrm{SR}^{89}$ and the consensus of the last AAP Regeneration Workshop ${ }^{88}$ demonstrated that regenerative therapy is a feasible alternative to achieve predictable clinical outcomes for the treatment of furcation defect involvement, with class II defects representing the highest predictable scenario. Moreover, the application of combined therapies (barriers, APC, EMD, BG) appears to offer an advantage over single therapeutic strategies. ${ }^{94}$

Regarding histological evidence of periodontal regeneration, few clinical studies in humans have investigated and demonstrated it in teeth with class II furcation involvement with partial defect closure. $95,96,97,98$ Complete regeneration of class II furcation involvement was obtained following combination of BG (DFDBA - demineralized freeze-dried bone allograft), ${ }^{66,98}$ biological agent (RhPDGF-BB - recombinant human platelet-derived growth factor-BB), ${ }^{95,98}$ and GTR. ${ }^{96,97}$

The predictability of the regenerative intervention, independently of the technique or biomaterial used, is affected by many clinical factors. These factors are related to general aspects associated with the patient and local characteristics correlated with the defect. Factors related to the surgical technique are also important. Among the patient-related aspects, the following are highlighted: systemic health status, patient compliance in self-performed biofilm control, ${ }^{99}$ residual periodontal infections, ${ }^{100}$ and smoking status. ${ }^{101}$ Regarding the clinical characteristics of the defect, the most important are: interproximal bone levels, gingival thickness, furcation and residual osseous morphologies, radicular anatomy, radicular divergence, and root trunk length. ${ }^{102}$ Regenerative procedures in furcation defects also require the abovementioned concepts, including careful flap design, proper root preparation, wound closure, careful membrane placement (GTR), and critical postoperative care. ${ }^{103,104}$

Several studies using GTR have demonstrated that furcation defect dimensions (depth and width) influence the amount of clinical attachment gain and bone fill $82,87,90,102,105,106,107$ The predictability of the regenerative approach increases if the furcation defect presents a deep vertical extension while maintaining the interproximal bone level in the vicinity of the cementoenamel junction (CEJ). The interproximal bone level facilitates the retention of the membrane in a proper position, allowing the repositioning of the surgical flap to the coronal position. ${ }^{102}$ An involved tooth's prognosis also improves with a thick gingival tissue, which provides more resistance to ischemia when the mucoperiosteal flap is placed over a nonvascularized membrane. ${ }^{108}$ Moreover, the long root trunk facilitates the placement of a barrier membrane under the CEJ to achieve full coverage of the furcation entrance. ${ }^{109}$

Taken together, to improve the predictability of regenerative approaches, the risk factors and adverse systemic factors should be controlled whenever possible, and meticulous postoperative care should be implemented to maintain sustainable long-term outcomes. ${ }^{88}$

\section{Is it possible to maintain the benefit in the long term for furcations?}

Several longitudinal clinical trials and SRs have investigated the long-term results after different treatment modalities of class II furcation involvements, varying from 2 to 10 years of follow-up. ${ }^{110-115}$ The majority of the studies explored the long-term efficacy of GTR in mandibular molars with class II defects. In this context, Machtei et al., ${ }^{115}$ in a longitudinal study with 5 years of follow-up, examined the efficacy of GTR for the treatment of class II furcation defects using expanded polytetrafluoroethylene membranes. The clinical improvement was stable or even further improved after 5 years in $90.7 \%$ of the teeth treated with GTR. Good oral hygiene care and frequent maintenance appointments were also essential to 
guarantee the results. ${ }^{115}$ Similarly, Eickholtz et al. ${ }^{112,113}$ investigated clinically and radiographically the long-term outcomes (5 and 10 years, respectively) of GTR using non-resorbable and resorbable membranes in class II furcation defects. In the study with 5 years of follow-up, ${ }^{112}$ the authors demonstrated significant improvement in horizontal attachment and bone gain for both groups (non-absorbable and absorbable barriers), and the results were stable in approximately $90 \%$ of the defects without differences between groups. In the 10-year follow-up results ${ }^{113}$ in the same group of patients, clinical improvements were maintained in $83 \%$ of the sample. ${ }^{113}$

A long-term comparison between GTR with absorbable barrier and OFD indicated that GTR gained significantly more horizontal attachment level and bone height after 2 years of follow-up. The authors concluded that GTR might lead to clinical improvements with the possibility of complete closure of some defects and stability over time. More recently, Majzoub et al. ${ }^{116}$ evaluated the clinical effects and survival rate of furcation class II treated with GTR. The 5- and 10-year survival rates of the treated teeth were $86.5 \%$ and $74.3 \%$, respectively.

\section{Does this benefit in furcations justify the greater initial costs?}

In the last forty years, a significant number of studies have evaluated the treatment of class II furcation with regenerative approaches, and the vast majority has supported significant clinical improvement with long-term stability. Among the advantages of regenerative therapy for class II furcation, we can highlight the possibility of complete closure or conversion to class I defects, favoring patient biofilm control and professional intervention during supportive periodontal care. Therefore, the costs associated with the initial procedures seem to be justified by the increased possibility of tooth retention on a long-term basis.

\section{Clinical significance: final considerations}

Overall, the data assessed above provide evidence of the regenerative potential of the periodontium.
According to the revised literature, the clinical benefits achievable with regenerative approaches, characterized by additional CAL gain, PPD reduction, and resolution/reduction of the intrabony component or furcation defect, may improve tooth prognosis by increasing tooth support, facilitating maintenance procedures and decreasing the site risk on the long-term basis. Furthermore, long-term follow-up evaluations published recently demonstrated the stability of the results among compliant patients receiving regular supportive periodontal care, ${ }^{34,117}$ while no additional benefit was observed in irregular SPT. ${ }^{118}$ However, a wide variability has been found regardless of the technique or concept used. This variability has been associated with individuals' and defects' characteristics or technical aspects of the surgical procedures. Throughout the text, we have addressed these limiting factors and the requisites for periodontal regeneration. To start answering the question proposed in the title, we may say that periodontal regeneration is only a goal when it is possible and predictable. It is imperative for the clinician to identify patients and clinical scenarios that would be benefited by the therapy.

Another crucial aspect to answer the title question is distinguishing statistically significant results from clinically relevant ones. The treat-to-target concept could be applied for regenerative procedures, defining prespecified endpoints that would have meaningful effects on the therapy, including change in prognosis, improvement in masticatory function, enhancement of esthetic results in the anterior region (avoiding black spaces), or more uncomplicated maintenance procedures. These "true" outcomes justify the higher initial cost of regenerative procedures, with better cost effectiveness in the long term.

Finally, patient preferences should be routinely incorporated in the planning and evaluation of the therapy. ${ }^{119}$ Although this seems like an obvious observation, few studies have addressed patient-centered outcomes, not only in periodontal but also in other oral regenerative procedures. ${ }^{120} \mathrm{~A}$ multicenter RCT compared healing, postoperative morbidity, and patient perception following regenerative therapy in which the papilla preservation flap technique was associated or not 
with enamel matrix derivatives. Both approaches result in high satisfaction levels after one year, without significant differences between them. The ability to preserve teeth and maintain/improve chewing were the factors most often cited as relevant by patients. ${ }^{121}$

\section{Conclusions}

a. In light of the discussed literature and its interpretation, seeking periodontal regeneration with currently available regenerative techniques is still a goal as long as some essential conditions are fulfilled: b. Periodontal regeneration in its classical histological definition is not measurable clinically and may be unpredictable.

c. Predictable and clinically relevant results may be expected in the treatment of deep intrabony defects associated with residual pockets and buccal/lingual class II furcation defects, as long as a careful case selection is made based on several patient and/or site features.

d. Results are technically sensitive. Minimally invasive principles and papillary preservation flaps should be considered whenever possible.

e. Periodontal maintenance is crucial for any therapy and plays a key role in the long-term prognosis.

\section{References}

1. Younger WJ. Some of the latest phases in implantation and other operations. Dent Cosmos. 1983;35(2):102-8.

2. Susin C, Wikesjö UM. Regenerative periodontal therapy: 30 years of lessons learned and unlearned. Periodontol 2000. 2013 Jun;62(1):232-42. https://doi.org/10.1111/prd.12003

3. Susin C, Fiorini T, Lee J, De Stefano JA, Dickinson DP, Wikesjö UM. Wound healing following surgical and regenerative periodontal therapy. Periodontol 2000. 2015 Jun;68(1):83-98. https://doi.org/10.1111/prd.12057

4. Retzepi M, Tonetti M, Donos N. Gingival blood flow changes following periodontal access flap surgery using laser Doppler flowmetry. J Clin Periodontol. 2007 May;34(5):437-43. https://doi.org/10.1111/j.1600-051X.2007.01062.x

5. Retzepi M, Tonetti M, Donos N. Comparison of gingival blood flow during healing of simplified papilla preservation and modified Widman flap surgery: a clinical trial using laser Doppler flowmetry. J Clin Periodontol. 2007 Oct;34(10):903-11. https://doi.org/10.1111/j.1600-051X.2007.01119.x

6. Burkhardt R, Lang NP. Coverage of localized gingival recessions: comparison of micro- and macrosurgical techniques. J Clin Periodontol. 2005 Mar;32(3):287-93. https://doi.org/10.1111/j.1600-051X.2005.00660.x

7. Melcher AH. On the repair potential of periodontal tissues. J Periodontol. 1976 May;47(5):256-60. https://doi.org/10.1902/jop.1976.47.5.256

8. Polimeni G, Koo KT, Qahash M, Xiropaidis AV, Albandar JM, Wikesjö UM. Prognostic factors for alveolar regeneration: effect of tissue occlusion on alveolar bone regeneration with guided tissue regeneration. J Clin Periodontol. 2004 Sep;31(9):730-5. https://doi.org/10.1111/j.1600-051X.2004.00543.x

9. Wikesjö UM, Lim WH, Thomson RC, Hardwick WR. Periodontal repair in dogs: gingival tissue occlusion, a critical requirement for GTR? J Clin Periodontol. 2003 Jul;30(7):655-64. https://doi.org/10.1034/j.1600-051X.2003.00362.x

10. Polimeni G, Koo KT, Qahash M, Xiropaidis AV, Albandar JM, Wikesiö UM. Prognostic factors for alveolar regeneration: effect of a space-providing biomaterial on guided tissue regeneration. J Clin Periodontol. 2004 Sep;31(9):725-9. https://doi.org/10.1111/j.1600-051X.2004.00542.x

11. Polimeni G, Albandar JM, Wikesjö UM. Prognostic factors for alveolar regeneration: effect of space provision. J Clin Periodontol. 2005 Sep;32(9):951-4. https://doi.org/10.1111/j.1600-051X.2005.00763.x

12. Garcia J, Dodge A, Luepke P, Wang HL, Kapila Y, Lin GH. Effect of membrane exposure on guided bone regeneration: A systematic review and meta-analysis. Clin Oral Implants Res. 2018 Mar;29(3):328-38. https://doi.org/10.1111/clr.13121

13. Wikesjö UM, Nilvéus R. Periodontal repair in dogs: effect of wound stabilization on healing. J Periodontol. 1990 Dec;61(12):719-24. https://doi.org/10.1902/jop.1990.61.12.719

14. Wikesjö UM, Claffey N, Egelberg J. Periodontal repair in dogs. Effect of heparin treatment of the root surface. J Clin Periodontol. 1991 Jan;18(1):60-4. https://doi.org/10.1111/j.1600-051X.1991.tb01120.x

15. Ireton JE, Unger JG, Rohrich RJ. The role of wound healing and its everyday application in plastic surgery: a practical perspective and systematic review. Plast Reconstr Surg Glob Open. 2013 May;1(1):e10-e19. https://doi.org/10.1097/GOX.0b013e31828ff9f4 
16. Papapanou PN, Tonetti MS. Diagnosis and epidemiology of periodontal osseous lesions. Periodontol 2000. 2000 Feb;22(1):8-21. https://doi.org/10.1034/j.1600-0757.2000.2220102.x

17. Goldman HM, Cohen DW. The infrabony pocket: classification and treatment. J Periodontol. 1958;29(4):272-91. https://doi.org/10.1902/jop.1958.29.4.272

18. Nielsen IM, Glavind L, Karring T. Interproximal periodontal intrabony defects. Prevalence, localization and etiological factors. J Clin Periodontol. 1980 Jun;7(3):187-98. https://doi.org/10.1111/j.1600-051X.1980.tb01962.x

19. Ainamo A, Soikkonen K, Wolf J, Siukosaari P, Erkinjuntti T, Tilvis R, et al. Dental radiographic findings in the elderly in Helsinki, Finland. Acta Odontol Scand. 1994 Aug;52(4):243-9. https://doi.org/10.3109/00016359409029053

20. Larato DC. Intrabony defects in the dry human skull. J Periodontol. 1970 Sep;41(9):496-8. https://doi.org/10.1902/jop.1970.41.9.496

21. Larato DC. Periodontal bone defects in the juvenile skull. J Periodontol. 1970 Aug;41(8):473-5. https://doi.org/10.1902/jop.1970.41.8.473

22. Papapanou PN, Wennström JL. The angular bony defect as indicator of further alveolar bone loss. J Clin Periodontol. 1991 May;18(5):317-22. https://doi.org/10.1111/j.1600-051X.1991.tb00435.x

23. Papapanou PN, Wennström JL, Gröndahl K. Periodontal status in relation to age and tooth type: a cross-sectional radiographic study. J Clin Periodontol. 1988 Aug;15(7):469-78. https://doi.org/10.1111/i.1600-051X.1988.tb01602.x

24. Söder B, Jin LJ, Söder PO, Wikner S. Clinical characteristics of destructive periodontitis in a risk group of Swedish urban adults. Swed Dent J. 1995;19(1-2):9-15.

25. Wouters FR, Salonen LE, Helldén LB, Frithiof L. Prevalence of interproximal periodontal intrabony defects in an adult population in Sweden: a radiographic study. J Clin Periodontol. 1989 Mar;16(3):144-9. https://doi.org/10.1111/j.1600-051X.1989.tb01631.x

26. Matuliene G, Pietursson BE, Salvi GE, Schmidlin K, Brägger U, Zwahlen M, et al. Influence of residual pockets on progression of periodontitis and tooth loss: results after 11 years of maintenance. J Clin Periodontol. 2008 Aug;35(8):685-95. https://doi.org/10.1111/j.1600-051X.2008.01245.x

27. McGuire MK, Nunn ME. Prognosis versus actual outcome. II. The effectiveness of clinical parameters in developing an accurate prognosis. J Periodontol. 1996 Jul;67(7):658-65. https://doi.org/10.1902/jop.1996.67.7.658

28. Papapanou PN, Sanz M, Buduneli N, Dietrich T, Feres M, Fine DH, et al. Periodontitis: Consensus report of workgroup 2 of the 2017 World Workshop on the Classification of Periodontal and Peri-Implant Diseases and Conditions. J Clin Periodontol. 2018 Jun;45 Suppl 20:S162-70. https://doi.org/10.1111/icpe.12946

29. Cortellini P, Tonetti MS. Clinical concepts for regenerative therapy in intrabony defects. Periodontol 2000. 2015 Jun;68(1):282-307. https://doi.org/10.1111/prd.12048

30. Elangovan S. Treatment of Select Intrabony Defects by Periodontal Regeneration Could Be Cost-effective Long Term in Compliant Patients. J Evid Based Dent Pract. 2016 Dec;16(4):243-5. https://doi.org/10.1016/i.jebdp.2016.11.004

31. Ivanovic A, Nikou G, Miron RJ, Nikolidakis D, Sculean A. Which biomaterials may promote periodontal regeneration in intrabony periodontal defects? A systematic review of preclinical studies. Quintessence Int. 2014 May;45(5):385-95.

32. Ivanovski S. Periodontal regeneration. Aust Dent J. 2009 Sep;54 Suppl 1:S118-28. https://doi.org/10.1111/j.1834-7819.2009.01150.x

33. Nibali L, Koidou VP, Nieri M, Barbato L, Pagliaro U, Cairo F. Regenerative surgery versus access flap for the treatment of intra-bony periodontal defects: a systematic review and meta-analysis. J Clin Periodontol. 2020 Jul;47(S22 Suppl 22):320-51. https://doi.org/10.1111/icpe.13237

34. Wu YC, Lin LK, Song CJ, Su YX, Tu YK. Comparisons of periodontal regenerative therapies: A meta-analysis on the long-term efficacy. J Clin Periodontol. 2017 May;44(5):511-9. https://doi.org/10.1111/icpe.12715

35. Sculean A, Nikolidakis D, Nikou G, Ivanovic A, Chapple IL, Stavropoulos A. Biomaterials for promoting periodontal regeneration in human intrabony defects: a systematic review. Periodontol 2000. 2015 Jun;68(1):182-216. https://doi.org/10.1111/prd.12086

36. Annunziata M, Piccirillo A, Perillo F, Cecoro G, Nastri L, Guida L. Enamel matrix derivative and autogenous bone graft for periodontal regeneration of intrabony defects in humans: a systematic review and meta-analysis. materials (Basel). 2019 Aug;12(16):E2634. https://doi.org/10.3390/mal2162634

37. Cãlin C, Pãtraşcu I. Growth factors and beta-tricalcium phosphate in the treatment of periodontal intraosseous defects: a systematic review and meta-analysis of randomised controlled trials. Arch Oral Biol. 2016 Jun;66:44-54. https://doi.org/10.1016/i.archoralbio.2016.02.007

38. Darby IB, Morris KH. A systematic review of the use of growth factors in human periodontal regeneration. J Periodontol. 2013 Apr;84(4):465-76. https://doi.org/10.1902/jop.2012.120145

39. Del Fabbro M, Bortolin M, Taschieri S, Weinstein R. Is platelet concentrate advantageous for the surgical treatment of periodontal diseases? A systematic review and meta-analysis. J Periodontol. 2011 Aug;82(8):1100-11. https://doi.org/10.1902/jop.2010.100605

40. Esposito M, Grusovin MG, Papanikolaou N, Coulthard P, Worthington HV. Enamel matrix derivative (Emdogain(R)) for periodontal tissue regeneration in intrabony defects. Cochrane Database Syst Rev. 2009 Oct;(4):CD003875. https://doi.org/10.1002/14651858.CD003875.pub3 
Periodontal regeneration: is it still a goal in clinical periodontology?

41. Hou X, Yuan J, Aisaiti A, Liu Y, Zhao J. The effect of platelet-rich plasma on clinical outcomes of the surgical treatment of periodontal intrabony defects: a systematic review and meta-analysis. BMC Oral Health. 2016 Aug;16(1):71. https://doi.org/10.1186/s12903-016-0261-5

42. Kao RT, Nares S, Reynolds MA. Periodontal regeneration - intrabony defects: a systematic review from the AAP Regeneration Workshop. J Periodontol. 2015 Feb;86(2 Suppl):S77-104. https://doi.org/10.1902/jop.2015.130685

43. Khojasteh A, Behnia H, Naghdi N, Esmaeelinejad M, Alikhassy Z, Stevens M. Effects of different growth factors and carriers on bone regeneration: a systematic review. Oral Surg Oral Med Oral Pathol Oral Radiol. 2013 Dec;116(6):e405-23. https://doi.org/10.1016/i.0000.2012.01.044

44. Koop R, Merheb J, Quirynen M. Periodontal regeneration with enamel matrix derivative in reconstructive periodontal therapy: a systematic review. J Periodontol. 2012 Jun;83(6):707-20. https://doi.org/10.1902/jop.2011.110266

45. Matarasso M, lorio-Siciliano V, Blasi A, Ramaglia L, Salvi GE, Sculean A. Enamel matrix derivative and bone grafts for periodontal regeneration of intrabony defects: a systematic review and meta-analysis. Clin Oral Investig. 2015 Sep;19(7):1581-93. https://doi.org/10.1007/s00784-015-1491-7

46. Miron RJ, Zucchelli G, Pikos MA, Salama M, Lee S, Guillemette V, et al. Use of platelet-rich fibrin in regenerative dentistry: a systematic review. Clin Oral Investig. $2017 \mathrm{Jul}$;21(6):1913-27. https://doi.org/10.1007/s00784-017-2133-z

47. Needleman IG, Worthington HV, Giedrys-Leeper E, Tucker RJ. Guided tissue regeneration for periodontal infra-bony defects. Cochrane Database Syst Rev. 2006 Apr;(2):CD001724. https://doi.org/10.1002/14651858.CD001724.pub2

48. Pagliaro U, Nieri M, Rotundo R, Cairo F, Carnevale G, Esposito M, et al. Clinical guidelines of the Italian Society of Periodontology for the reconstructive surgical treatment of angular bony defects in periodontal patients. J Periodontol. 2008 Dec;79(12):2219-32. https://doi.org/10.1902/jop.2008.080266

49. Panda S, Doraiswamy J, Malaiappan S, Varghese SS, Del Fabbro M. Additive effect of autologous platelet concentrates in treatment of intrabony defects: a systematic review and meta-analysis. J Investig Clin Dent. 2016 Feb;7(1):13-26. https://doi.org/10.1111/iicd.12117

50. Parrish LC, Miyamoto T, Fong N, Mattson JS, Cerutis DR. Non-bioabsorbable vs. bioabsorbable membrane: assessment of their clinical efficacy in guided tissue regeneration technique. A systematic review. J Oral Sci. 2009 Sep;51(3):383-400. https://doi.org/10.2334/josnusd.51.383

51. Patel RA, Wilson RF, Palmer RM. The effect of smoking on periodontal bone regeneration: a systematic review and meta-analysis. J Periodontol. 2012 Feb;83(2):143-55. https://doi.org/10.1902/jop.2011.110130

52. Rathe F, Junker R, Chesnutt BM, Jansen JA. The effect of enamel matrix derivative (Emdogain) on bone formation: a systematic review. Tissue Eng Part B Rev. 2009 Sep;15(3):215-24. https://doi.org/10.1089/ten.teb.2008.0065

53. Reynolds MA, Aichelmann-Reidy ME, Branch-Mays GL, Gunsolley JC. The efficacy of bone replacement grafts in the treatment of periodontal osseous defects. A systematic review. Ann Periodontol. 2003 Dec;8(1):227-65. https://doi.org/10.1902/annals.2003.8.1.227

54. Roselló-Camps À, Monje A, Lin GH, Khoshkam V, Chávez-Gatty M, Wang HL, et al. Platelet-rich plasma for periodontal regeneration in the treatment of intrabony defects: a meta-analysis on prospective clinical trials. Oral Surg Oral Med Oral Pathol Oral Radiol. 2015 Nov; 120(5):562-74. https://doi.org/10.1016/i.0000.2015.06.035

55. Stoecklin-Wasmer C, Rutjes AW, Costa BR, Salvi GE, Jüni P, Sculean A. Absorbable collagen membranes for periodontal regeneration: a systematic review. J Dent Res. 2013 Sep;92(9):773-81. https://doi.org/10.1177/0022034513496428

56. Troiano G, Laino L, Zhurakivska K, Cicciù M, Lo Muzio L, Lo Russo L. Addition of enamel matrix derivatives to bone substitutes for the treatment of intrabony defects: A systematic review, meta-analysis and trial sequential analysis. J Clin Periodontol. 2017 Jul;44(7):729-38. https://doi.org/10.1111/icpe.12742

57. Trombelli L, Heitz-Mayfield LJ, Needleman I, Moles D, Scabbia A. A systematic review of graft materials and biological agents for periodontal intraosseous defects. J Clin Periodontol. 2002;29 Suppl 3:117-35. https://doi.org/10.1034/j.1600-051X.29.s3.7.x

58. Zanatta FB, Souza FG, Pinto TM, Antoniazzi RP, Rösing CK. Do the clinical effects of enamel matrix derivatives in infrabony defects decrease overtime? A systematic review and meta-analysis. Braz Dent J. 2013 Sep-Oct;24(5):446-55. https://doi.org/10.1590/0103-6440201302192

59. Zhou S, Sun C, Huang S, Wu X, Zhao Y, Pan C, et al. Efficacy of adjunctive bioactive materials in the treatment of periodontal intrabony defects: a systematic review and meta-analysis. BioMed Res Int. 2018 May;2018:8670832. https://doi.org/10.1155/2018/8670832

60. Murphy KG, Gunsolley JC. Guided tissue regeneration for the treatment of periodontal intrabony and furcation defects: a systematic review. Ann Periodontol. 2003 Dec;8(1):266-302. https://doi.org/10.1902/annals.2003.8.1.266

61. Tu YK, Needleman I, Chambrone L, Lu HK, Faggion Junior CM. A Bayesian network meta-analysis on comparisons of enamel matrix derivatives, guided tissue regeneration and their combination therapies. J Clin Periodontol. 2012 Mar;39(3):303-14. https://doi.org/10.1111/j.1600-051X.2011.01844.x

62. Tonetti MS, Lang NP, Cortellini P, Suvan JE, Adriaens P, Dubravec D, et al. Enamel matrix proteins in the regenerative therapy of deep intrabony defects. J Clin Periodontol. 2002 Apr;29(4):317-25. https://doi.org/10.1034/j.1600-051X.2002.290407.x 
63. Rösing CK, Aass AM, Mavropoulos A, Gjermo P. Clinical and radiographic effects of enamel matrix derivative in the treatment of intrabony periodontal defects: a 12-month longitudinal placebo-controlled clinical trial in adult periodontitis patients. J Periodontol. 2005 Jan;76(1):129-33. https://doi.org/10.1902/jop.2005.76.1.129

64. Sanz M, Herrera D, Kebschull M, Chapple I, Jepsen S, Beglundh T, et al. Treatment of stage I-III periodontitis-The EFP S3 level clinical practice guideline. J Clin Periodontol. 2020 Jul;47(S22 Suppl 22):4-60. https://doi.org/10.1111/icpe.13290

65. Cortellini P, Carnevale G, Sanz M, Tonetti MS. Treatment of deep and shallow intrabony defects. A multicenter randomized controlled clinical trial. J Clin Periodontol. 1998 Dec;25(12):981-7. https://doi.org/10.1111/j.1600-051X.1998.tb02402.x

66. Cortellini P, Stalpers G, Pini Prato G, Tonetti MS. Long-term clinical outcomes of abutments treated with guided tissue regeneration. J Prosthet Dent. 1999 Mar;81(3):305-11. https://doi.org/10.1016/S0022-3913(99)70274-X

67. Tsitoura E, Tucker R, Suvan J, Laurell L, Cortellini P, Tonetti M. Baseline radiographic defect angle of the intrabony defect as a prognostic indicator in regenerative periodontal surgery with enamel matrix derivative. J Clin Periodontol. 2004 Aug;31 (8):643-7. https://doi.org/10.1111/j.1600-051X.2004.00555.x

68. Liñares A, Cortellini P, Lang NP, Suvan J, Tonetti MS). Guided tissue regeneration/deproteinized bovine bone mineral or papilla preservation flaps alone for treatment of intrabony defects. II: radiographic predictors and outcomes. J Clin Periodontol. 2006 May;33(5):351-8. https://doi.org/10.1111/j.1600-051X.2006.00911.x

69. Cortellini P, Tonetti MS. Improved wound stability with a modified minimally invasive surgical technique in the regenerative treatment of isolated interdental intrabony defects. J Clin Periodontol. 2009 Feb;36(2):157-63. https://doi.org/10.1111/j.1600-051X.2008.01352.x

70. Cortellini P, Buti J, Pini Prato G, Tonetti MS. Periodontal regeneration compared with access flap surgery in human intra-bony defects 20 -year follow-up of a randomized clinical trial: tooth retention, periodontitis recurrence and costs. J Clin Periodontol. 2017 Jan;44(1):58-66. https://doi.org/10.1111/icpe.12638

71. Liu S, Hu B, Zhang Y, Li W, Song J. Minimally invasive surgery combined with regenerative biomaterials in treating intra-bony defects: a meta-analysis. PLoS One. 2016 Jan;11(1):e0147001. https://doi.org/10.1371/journal.pone.0147001

72. American Academy of Periodontology. Glossary of periodontal terms. 4th ed. Chicago, IL, USA: American Academy of Periodontology; 2001.

73. Hamp SE, Nyman S, Lindhe J. Periodontal treatment of multirooted teeth. Results after 5 years. J Clin Periodontol. 1975 Aug;2(3):126-35. https://doi.org/10.1111/j.1600-051X.1975.tb01734.x

74. Tarnow D, Fletcher P. Classification of the vertical component of furcation involvement. J Periodontol. 1984 May;55(5):283-4. https://doi.org/10.1902/jop.1984.55.5.283

75. Becker W, Berg L, Becker BE. Untreated periodontal disease: a longitudinal study. J Periodontol. 1979 May;50(5):234-44. https://doi.org/10.1902/jop.1979.50.5.234

76. Lindhe J, Okamoto H, Yoneyama T, Haffajee A, Socransky SS. Longitudinal changes in periodontal disease in untreated subjects. J Clin Periodontol. 1989 Nov;16(10):662-70. https://doi.org/10.1111/i.1600-051X.1989.tb01037.x

77. Axelsson P, Lindhe J, Nyström B. On the prevention of caries and periodontal disease. Results of a 15 -year longitudinal study in adults. J Clin Periodontol. 1991 Mar;18(3):182-9. https://doi.org/10.1111/j.1600-051X.1991.tb01131.x

78. Goldman MJ, Ross IF, Goteiner D. Effect of periodontal therapy on patients maintained for 15 years or longer. A retrospective study. J Periodontol. 1986 Jun;57(6):347-53. https://doi.org/10.1902/jop.1986.57.6.347

79. Hirschfeld L, Wasserman B. A long-term survey of tooth loss in 600 treated periodontal patients. J Periodontol. 1978 May;49(5):225-37. https://doi.org/10.1902/jop.1978.49.5.225

80. McFall WT Jr. Tooth loss in 100 treated patients with periodontal disease: a long-term study. J Periodontol. 1982 Sep;53(9):539-49. https://doi.org/10.1902/jop.1982.53.9.539

81. Salvi GE, Mischler DC, Schmidlin K, Matuliene G, Pjetursson BE, Brägger U, et al. Risk factors associated with the longevity of multi-rooted teeth: long-term outcomes after active and supportive periodontal therapy. J Clin Periodontol. 2014 Jul;41(7):701-7. https://doi.org/10.1111/jcpe.12266

82. Casarin RC, Ribeiro EP, Ribeiro FV, Nociti Junior FH, Sallum AW, Sallum EA, et al. Influence of anatomic features on the effectiveness of enamel matrix derivative proteins in the treatment of proximal Class II furcation involvements. Quintessence Int. 2009 Oct;40(9):753-61.

83. Santana RB, Uzel MI, Gusman H, Gunaydin Y, Jones JA, Leone CW. Morphometric analysis of the furcation anatomy of mandibular molars. J Periodontol. 2004 Jun;75(6):824-9. https://doi.org/10.1902/jop.2004.75.6.824

84. Jepsen S, Gennai S, Hirschfeld J, Kalemai Z, Buti J, Graziani F. Regenerative surgical treatment of furcation defects: a systematic review and Bayesian network meta-analysis of randomized clinical trials. J Clin Periodontol. 2020 Jul;47(S22 Suppl 22):352-74. https://doi.org/10.1111/icpe.13238

85. Dommisch H, Walter C, Dannewitz B, Eickholz P. Resective surgery for the treatment of furcation involvement: a systematic review. J Clin Periodontol. 2020 Jul;47(S22 Suppl 22):375-91. https://doi.org/10.1111/jcpe.13241

86. Schwendicke F, Graetz C, Stolpe M, Dörfer CE. Retaining or replacing molars with furcation involvement: a cost-effectiveness comparison of different strategies. J Clin Periodontol. 2014 Nov;41(11):1090-7. https://doi.org/10.1111/icpe.12315 
Periodontal regeneration: is it still a goal in clinical periodontology?

87. Jepsen S, Eberhard J, Herrera D, Needleman I. A systematic review of guided tissue regeneration for periodontal furcation defects. What is the effect of guided tissue regeneration compared with surgical debridement in the treatment of furcation defects? J Clin Periodontol. 2002;29 Suppl 3:103-16. https://doi.org/10.1034/i.1600-051X.29.s3.6.x

88. Reddy MS, Aichelmann-Reidy ME, Avila-Ortiz G, Klokkevold PR, Murphy KG, Rosen PS, et al. Periodontal regeneration furcation defects: a consensus report from the AAP Regeneration Workshop. J Periodontol. 2015 Feb;86(2 Suppl):S131-3. https://doi.org/10.1902/jop.2015.140379

89. Avila-Ortiz G, De Buitrago JG, Reddy MS. Periodontal regeneration - furcation defects: a systematic review from the AAP Regeneration Workshop. J Periodontol. 2015 Feb;86(2 Suppl):S108-30. https://doi.org/10.1902/jop.2015.13067790.

90. Kinaia BM, Steiger J, Neely AL, Shah M, Bhola M. Treatment of Class II molar furcation involvement: meta-analyses of reentry results. J Periodontol. 2011 Mar;82(3):413-28. https://doi.org/10.1902/jop.2010.100306

91. Chen TH, Tu YK, Yen CC, Lu HK, Lu H-K. A systematic review and meta-analysis of guided tissue regeneration/osseous grafting for the treatment of Class II furcation defects. J Dent Sci. 2013;8(3):209-24. https://doi.org/10.1016/i.jds.2013.06.006

92. Jepsen S, Heinz B, Jepsen K, Arjomand M, Hoffmann T, Richter S, et al. A randomized clinical trial comparing enamel matrix derivative and membrane treatment of buccal Class II furcation involvement in mandibular molars. Part I: study design and results for primary outcomes. J Periodontol. 2004 Aug;75(8):1150-60. https://doi.org/10.1902/jop.2004.75.8.1150

93. Masaeli R, Zandsalimi K, Lotfi Z, Tayebi L. Using enamel matrix derivative to improve treatment efficacy in periodontal furcation defects. J Prosthodont. 2018;27(8):733-6. https://doi.org/10.1111/jopr.12753

94. Queiroz LA, Santamaria MP, Casati MZ, Ruiz KS, Nociti F Jr, Sallum AW, et al. Enamel matrix protein derivative and/or synthetic bone substitute for the treatment of mandibular class II buccal furcation defects: a 12-month randomized clinical trial. Clin Oral Investig. 2016 Sep;20(7):1597-606. https://doi.org/10.1007/s00784-015-1642-x

95. Camelo M, Nevins ML, Schenk RK, Lynch SE, Nevins M. Periodontal regeneration in human Class II furcations using purified recombinant human platelet-derived growth factor-BB (rhPDGF-BB) with bone allograft. Int J Periodontics Restorative Dent. 2003 Jun;23(3):213-25.

96. Stoller NH, Johnson LR, Garrett S. Periodontal regeneration of a class II furcation defect utilizing a bioabsorbable barrier in a human: a case study with histology. J Periodontol. 2001 Feb;72(2):238-42. https://doi.org/10.1902/jop.2001.72.2.238

97. Harris RJ. Treatment of furcation defects with an allograft-alloplast-tetracycline composite bone graft combined with GTR: human histologic evaluation of a case report. Int J Periodontics Restorative Dent. 2002 Aug;22(4):381-7.

98. Nevins M, Camelo M, Nevins ML, Schenk RK, Lynch SE. Periodontal regeneration in humans using recombinant human platelet-derived growth factor-BB (rhPDGF-BB) and allogenic bone. J Periodontol. 2003 Sep;74(9):1282-92. https://doi.org/10.1902/jop.2003.74.9.1282

99. Cortellini P, Pini-Prato G, Tonetti M. Periodontal regeneration of human infrabony defects (V). Effect of oral hygiene on long-term stability. J Clin Periodontol. 1994 Oct;21(9):606-10. https://doi.org/10.1111/j.1600-051X.1994.tb00751.x

100. Machtei EE, Cho MI, Dunford R, Norderyd J, Zambon JJ, Genco RJ. Clinical, microbiological, and histological factors which influence the success of regenerative periodontal therapy. J Periodontol. 1994 Feb;65(2):154-61. https://doi.org/10.1902/jop.1994.65.2.154

101. Tonetti MS, Pini-Prato G, Cortellini P. Effect of cigarette smoking on periodontal healing following GTR in infrabony defects: a preliminary retrospective study. J Clin Periodontol. 1995 Mar;22(3):229-34. https://doi.org/10.1111/j.1600-051X.1995.tb00139.x

102. Sanz M, Giovannoli JL. Focus on furcation defects: guided tissue regeneration. Periodontol 2000. 2000 Feb;22(1):169-89. https://doi.org/10.1034/j.1600-0757.2000.2220111.x

103. Caffesse RG, SMith BA, Duff B, Morrison EC, Merrill D, Becker W. Class II furcations treated by guided tissue regeneration in humans: case reports. J Periodontol. 1990 Aug;61(8):510-4. https://doi.org/10.1902/jop.1990.61.8.510

104. Pontoriero R, Lindhe J, Nyman S, Karring T, Rosenberg E, Sanavi F. Guided tissue regeneration in the treatment of furcation defects in mandibular molars: a clinical study of degree III involvements. J Clin Periodontol. 1989 Mar;16(3):170-4. https://doi.org/10.1111/j.1600-051X.1989.tb01635.x

105. Cortellini P, Pini Prato G, Tonetti MS. Periodontal regeneration of human infrabony defects. II. Re-entry procedures and bone measures. J Periodontol. 1993 Apr;64(4):261-8. https://doi.org/10.1902/jop.1993.64.4.261

106. Machtei EE. Outcome variables for the study of periodontal regeneration. Ann Periodontol. 1997 Mar;2(1):229-39. https://doi.org/10.1902/annals.1997.2.1.229

107. Cury PR, Jeffcoat MK, Sallum AW, Cafesse R, Nociti Júnior FH, Sallum EA. Clinical and radiographic evaluation of guided tissue regeneration in the treatment of class II furcation defects: a randomized clinical trial. Am J Dent. 2003 Sep;16(Spec No):13A-6A.

108. Anderegg CR, Metzler DG, Nicoll BK. Gingiva thickness in guided tissue regeneration and associated recession at facial furcation defects. J Periodontol. 1995 May;66(5):397-402. https://doi.org/10.1902/jop.1995.66.5.397

109. Sallum EA, Ribeiro FV, Ruiz KS, Sallum AW. Experimental and clinical studies on regenerative periodontal therapy. Periodontol 2000. 2019 Feb;79(1):22-55. https://doi.org/10.1111/prd.12246

110. Cury PR, Sallum EA, Nociti Junior FH, Sallum AW, Jeffcoatt MK. Long-term results of guided tissue regeneration therapy in the treatment of class II furcation defects: a randomized clinical trial. J Periodontol. 2003 Jan;74(1):3-9. https://doi.org/10.1902/jop.2003.74.1.3 
111. Deo V, Gupta S, Ansari S, Kumar P, Yadav R. Evaluation of effectiveness of connective tissue graft as a barrier with bioresorbable collagen membrane in the treatment of mandibular Class II furcation defects in humans: 4 -year clinical results. Quintessence Int. 2014 Jan;45(1):15-22.

112. Eickholz P, Kim TS, Holle R, Hausmann E. Long-term results of guided tissue regeneration therapy with non-resorbable and bioabsorbable barriers. I. Class II furcations. J Periodontol. 2001 Jan;72(1):35-42. https://doi.org/10.1902/jop.2001.72.1.35

113. Eickholz P, Pretzl B, Holle R, Kim TS. Long-term results of guided tissue regeneration therapy with non-resorbable and bioabsorbable barriers. III. Class II furcations after 10 years. J Periodontol. 2006 Jan;77(1):88-94. https://doi.org/10.1902/jop.2006.77.1.88

114. Graziani F, Gennai S, Karapetsa D, Rosini S, Filice N, Gabriele M, et al. Clinical performance of access flap in the treatment of class Il furcation defects: a systematic review and meta-analysis of randomized clinical trials. J Clin Periodontol. 2015 Feb;42(2):169-81. https://doi.org/10.1111/jicpe.12327

115. Machtei EE, Grossi SG, Dunford R, Zambon JJ, Genco RJ. Long-term stability of Class II furcation defects treated with barrier membranes. J Periodontol. 1996 May;67(5):523-7. https://doi.org/10.1902/jop.1996.67.5.523

116. Majzoub J, Barootchi S, Tavelli L, Wang CW, Travan S, Wang HL. Treatment effect of guided tissue regeneration on the horizontal and vertical components of furcation defects: A retrospective study. J Periodontol. 2020 Sep;91(9):1148-58. https://doi.org/10.1002/JPER.19-0529

117. Cortellini P, Stalpers G, Mollo A, Tonetti MS. Periodontal regeneration versus extraction and dental implant or prosthetic replacement of teeth severely compromised by attachment loss to the apex: a randomized controlled clinical trial reporting 10-year outcomes, survival analysis and mean cumulative cost of recurrence. J Clin Periodontol. 2020 Jun;47(6):768-76. https://doi.org/10.1111/icpe.13289

118. Petsos H, Ratka-Krüger P, Neukranz E, Raetzke P, Eickholz P, Nickles K. Infrabony defects 20 years after open flap debridement and guided tissue regeneration. J Clin Periodontol. 2019 May;46(5):552-63. https://doi.org/10.1111/icpe.13110

119. Inglehart MR. Enhancing periodontal health through regenerative approaches: a commentary on the need for patient-reported outcomes. J Periodontol. 2015 Feb;86(2 Suppl):S4-7. https://doi.org/10.1902/jop.2015.140574

120. Mardas N, Trullenque-Eriksson A, MacBeth N, Petrie A, Donos N. Does ridge preservation following tooth extraction improve implant treatment outcomes: a systematic review: Group 4: Therapeutic concepts \& methods. Clin Oral Implants Res. 2015 Sep;26 Suppl 11:180-201. https://doi.org/10.1111/clr.12639

121. Tonetti MS, Fourmousis I, Suvan J, Cortellini P, Brägger U, Lang NP; European Research Group on Periodontology (ERGOPERIO). Healing, post-operative morbidity and patient perception of outcomes following regenerative therapy of deep intrabony defects. J Clin Periodontol. 2004 Dec;31(12):1092-8. https://doi.org/10.1111/j.1600-051X.2004.00615.x 